\title{
UNICA: variedad Peruana para mercado fresco y papa frita con tolerancia y resistencia para condiciones climáticas adversas
}

\author{
R.O. Gutiérrez-Rosales ${ }^{1}$, J. A. Espinoza-Trelles ${ }^{2}$, M. Bonierbale ${ }^{3}$
}

\begin{abstract}
RESUMEN
Las nuevas variedades de papa que se ofrecen a los agricultores deben tener ventajas intrínsecas, las mismas que deben ser superiores a las variedades existentes de uso tradicional. Esta variedad fue desarrollada por la División de Mejoramiento y Utilización de Recursos Genéticos del Centro Internacional de la Papa (CIP), con la colaboración de sus diferentes socios nacionales, entre los que destacan la Universidad Nacional San Luis Gonzaga de Ica, Perú. La reciente inscripción de la variedad UNICA en el Registro Nacional de Variedades Comerciales en el Servicio Nacional de Sanidad Agraria (SENASA), Perú; pone a disposición de los agricultores material genético, a partir de los sistemas formales de producción de semillas. Entre sus principales atributos resaltan la resistencia a virus (PVY), su tolerancia al calor, su moderada resistencia al nematodo del nudo (Meloidogyne ssp.), su precocidad, su estabilidad de rendimiento en varias épocas de siembra y su leve tolerancia a sales. En los últimos años a presentado un incremento de la oferta en los mercados de papa fresca y un posicionamiento en los mismos, debido a un mayor nivel de adopción entre los agricultores peruanos.
\end{abstract}

Palabras clave: Solanum tuberosum, papa, variedad, UNICA.

\section{UNICA: Peruvian cultivar for fresh market and french fries with new tolerance and resistance traits in adverse environment conditions}

\begin{abstract}
The new cultivar UNICA is advantageous over existing cultivars for warm areas, was developed by the Germplasm Enhancement and Crop Improvement Division of the International Potato Center (CIP), with the support of national partner, the National University San Luis Gonzaga, Ica, Peru. Its recent registration in the National Register of Commercial Cultivars in the National Plant Health Service (SENASA), Peru gives farmers access to seed from the formal seed system. Its main attributes is the resistance to virus $\mathrm{Y}$ (PVY), its tolerance to the heat in adverse climatic events its moderate resistance to root- knot nematode (Meloidogyne ssp.). Its slight tolerance to salt, and its fresh markets and suitability for the French Fry market. In the last years it has shown an increase supply in the fresh potato market and a greater level of adoption by the Peruvian farmers.
\end{abstract}

Key words: Solanum tuberosum, potato, cultivar, UNICA.

\footnotetext{
${ }^{1}$ Becario de Investigación, CIP-Lima. Correo electrónico: r.o.gutierrez@cgiar.org

${ }^{2}$ Asistente de Investigación, CIP-Lima.

${ }^{3}$ Jefe de la División, CIP-Lima. Germplasm Enhancement and Crop Improvement División, Centro Internacional de la Papa (CIP) - La Molina 1895, Apartado 1558, Lima 12, Perú.
} 


\section{Introducción}

UNICA es una variedad que fue seleccionada y evaluada por el CIP durante más de 7 años, sembrada en experimentos en más de 20 localidades. Tiene atributos de resistencia y precocidad que la hacen atractiva para los agricultores involucrados en el cultivo de papa. La adaptación de la UNICA a diferentes ambientes permite una amplia distribución geográfica, en regiones de la Costa y Sierra del Perú. Las buenas características para el consumo en fresco y para el procesamiento en tiras, representan una alternativa de mejores ingresos para los agricultores por la demanda que puede generar en el mercado.

\section{Origen}

La UNICA es el resultado de las investigaciones participativas con los agricultores (Asociaciones de Productores), las instituciones nacionales de investigación en el sector agrícola (Universidad Nacional "San Luis Gonzaga” de Ica) y el Centro Internacional de la Papa (CIP). El nombre de UNICA, es un reconocimiento a la Universidad Nacional "San Luis Gonzaga” de Ica, como alma mater de los profesionales en dicha región y representa una abreviación e iniciales de dicha universidad.

La selección inicialmente se realizó durante 3 años y en diferentes épocas, entre los cuales se incluyeron las progenies seleccionadas en el diseño genético (Línea $\mathrm{x}$ Probador). La genealogía de la UNICA se muestra en la Figura 1.

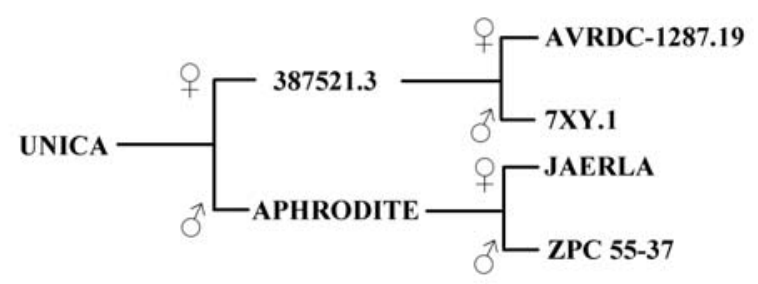

Figura 1. Genealogía de la variedad UNICA.
El clon identificado con el código del investigador o campo: C92.140 y con el código del CIP No. 392797.22, posteriormente fue denominado la variedad UNICA. El proceso iniciado el año 1991, tuvo tres fases (Mendoza et al., 2003): 1. Por resistencia a virus PVY (Potato Virus Y) y PVX (Potato Virus X), 2. Por tolerancia al virus PLRV (Potato Leaf Roll Virus) y al nematodo RKN (Root Knot Nematode) y 3. Por adaptabilidad a climas áridos y cálidos. Las primeras evaluaciones se realizaron en las Estaciones Experimentales del CIP (La Molina en Lima; Huancayo y San Ramón en Junín), y posteriormente en diversos valles de la costa peruana (Virú, Barranca, Cañete, Ica, Nasca, Majes, Tacna). Finalmente fueron seleccionados en los valles de Ica y Nasca con la aprobación de los agricultores e investigadores locales. En el año 1.998 (UNICA 1998), fue liberada a los agricultores por la Universidad Nacional San Luis Gonzaga de Ica y en el 2.005 fue inscrita en el Registro Nacional de Cultivares con el registro $N^{\circ}$ 001-2.005-AGSENASA-DGSV (SENASA 2005) con el apoyo de los fondos provenientes del Proyecto FONTAGRO.

\section{Descripción Varietal}

En general, la planta de la variedad UNICA es herbácea con hábito de crecimiento erecto, los tallos son gruesos de color verde oscuro, alcanzando una longitud entre 0,90 a 1,20 metros Las hojas son compuestas y se distribuyen en espiral sobre el tallo. La forma de la hoja es disectada, con cinco pares de foliolos laterales y un par de interhojuelas sobre los peciólulos. Tiene floración moderada entrada la temporada de primavera en Costa, escasa floración en el Invierno en Costa y ausencia de floración en condiciones de Sierra (mayor a $2.000 \mathrm{msnm}$ ); las flores son violetas y no forman bayas en épocas con bajas temperaturas. Los estolones son alargados en el Invierno o bajo condiciones de Sierra; ligeramente cortos y pegados al tallo en la primavera.

Los tubérculos son oblongos y alargados, con ojos superficiales y en la parte del ojo apical es semi-profundo. Se forman ligeras protuberancias en los ojos hacia finales de la primavera, 
volviéndose más liso en el invierno o bajo condiciones de Sierra. Estas protuberancias se presentan también cuando los niveles de nitrógeno elevados, cuando hay períodos de estrés hídrico prolongados o cuando se retrasa el período de cosecha.
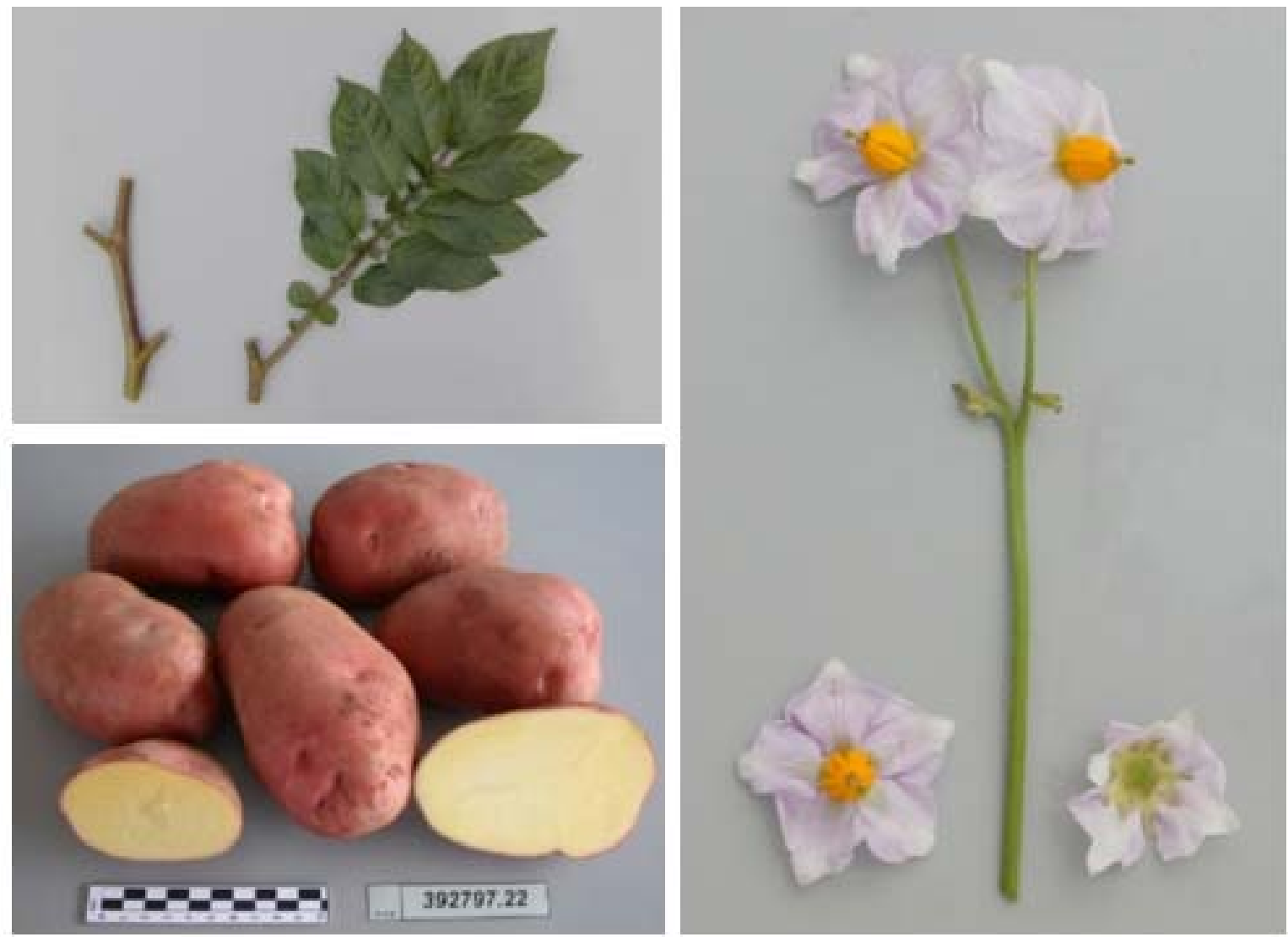

Figura 2. Imágenes del tallo, hoja, tubérculo y flor de la variedad (Foto: María Miki).

\section{Comportamiento Agronómico}

El período de dormancia de la semilla alcanza los 40 a 50 días, presenta ligera dominancia apical. El período vegetativo es precoz (70 a 90 dds) en condiciones de trópico alto o Sierra (2.000 a 3.800 msnm) para fines de multiplicación de semilla. Presenta características de semi-precoz (90 a 110 dds) en
La piel del tubérculo es de color rosado, que toma una tonalidad más clara hacia finales de la primavera en la Costa y es roja en condiciones de Sierra. La pulpa es crema (CIP, 1997 y 1998). Algunas imágenes de las características descritas pueden apreciarse en la Figura 2. 


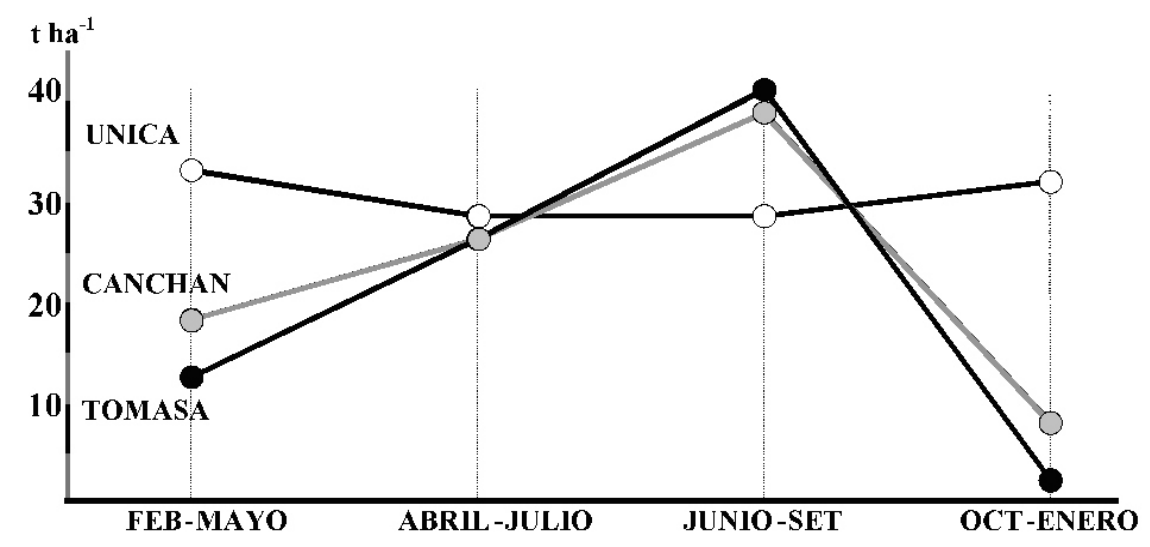

Figura 3. Estabilidad de la variedad UNICA (10 localidades de Costa, 1.995-1.996). Fuente: CIP, 1.998

Alto rendimiento potencial $\left(50 \mathrm{t} \cdot \mathrm{ha}^{-1}\right)$. Para el invierno en zonas de Costa Peruana (trópico bajo) y en épocas húmedas de la zona Sierra (trópico alto) se puede alcanzar el rendimiento potencial. En la primavera y en la época seca de las respectivas zonas se reduce el rendimiento. Comercialmente se pueden lograr rendimientos promedios de hasta $40 \mathrm{t} \cdot \mathrm{ha}^{-1}$.

Posee ligera tolerancia a sales y a temperaturas cálidas, pudiendo tuberizar con temperaturas nocturnas de hasta $16{ }^{\circ} \mathrm{C}$ (Vásquez, 2003), siendo una ventaja, pues en condiciones del fenómeno de El Niño, la producción de papa en la Costa Peruana se ve afectada por el incremento de la temperatura, inhibiéndose la tuberización en las variedades tradicionales. La amplia adaptabilidad a diferentes condiciones climáticas de la Costa, favorece la programación de las siembras y cosechas en una mayor amplitud de épocas (CIP, 1997 y 1998; UNICA, 1998). Fue evaluada en 13 localidades de la Costa y en 7 localidades de la Sierra del Perú (Tabla 1), desde el año 1.992 en que fue inicialmente selecto. Asimismo, fue sembrado entre los $8^{\circ}$ a $18^{\circ}$ de Latitud Sur, y en altitudes desde 80 a $3.800 \mathrm{msnm}$.

Los resultados en los ensayos para las localidades son diferentes, debido a la interacción del genotipo con el ambiente, donde hubo influencia de la época y de las condiciones de campo bajo las cuales se desarrollaron los experimentos. Los ensayos principalmente tenían unidades experimentales de 20 plantas, y entre tres a cuatro repeticiones. El diseño experimental utilizado fue bloques completos al azar (CIP, 1997 y 1998). La tolerancia al calor fue evaluada a partir de ambientes con temperaturas elevadas, en la épocas de la primavera y el verano en la región de la Costa Peruana, siendo las adecuadas para instalar estos experimentos; y cuantificándose los rendimientos de tubérculos $\left(\mathrm{t} \cdot h \mathrm{a}^{-1}\right)$, como una medida de la adaptación a estas condiciones (Tabla 2). Adicionalmente, el suelo de aquellas localidades que tenían una conductividad eléctrica superior a los $2 \mathrm{dS} \cdot \mathrm{m}^{-1}$ (suelos ligeramente salinos), fueron considerados como pruebas de tolerancia a sales, como es el caso de: Calana en Tacna (Verano-1.996), Majes en Arequipa (Verano-1.996), El Tambo en Arequipa (Invierno-1.996) y Moquegua (Invierno-1.996) (Tabla 2 y Tabla 3). Los resultados evidencian en la variedad UNICA una gran adaptación a diversos ambientes, para diferentes épocas de siembra, que en algunos casos superaban a los testigos o controles, como son las variedades tradicionales o locales (Canchan y Tomasa T.C.), especialmente en por su tolerancia al calor. 
Tabla 1. Lugares de Evaluación de la variedad UNICA

\begin{tabular}{|c|c|c|c|c|}
\hline Id & Lugar & Altitud (msnm) & Latitud & Año de evaluación \\
\hline 1 & Yungay, Ancash & 3.200 & $09^{\circ} 08^{\prime} \mathrm{S}$ & 1.995 \\
\hline 2 & Chaglla, Huánuco & 2.500 & $09^{\circ} 50^{\prime} \mathrm{S}$ & $2.001 / 2.002$ \\
\hline 3 & La Libertad, Huánuco & 3.000 & $10^{\circ} 04^{\prime} \mathrm{S}$ & 2.002 \\
\hline 4 & Huancayo, Junín & 3.500 & $11^{\circ} 57^{\prime} \mathrm{S}$ & $2.001 / 2.002$ \\
\hline 5 & Huasahuasi, Junín & 3.800 & $11^{\circ} 15^{\prime} \mathrm{S}$ & 2.003 \\
\hline 6 & Huamanga, Ayacucho & 2.500 & $13^{\circ} 09^{\prime} \mathrm{S}$ & 2.002 \\
\hline 7 & Chimbote, Ancash & 250 & $09^{\circ} 04^{\prime} \mathrm{S}$ & 1.996 \\
\hline 8 & Virú, La Libertad & 400 & $08^{\circ} 24^{\prime} \mathrm{S}$ & 1.996 \\
\hline 9 & Trujillo, La Libertad & 80 & $08^{\circ} 06^{\prime} \mathrm{S}$ & $1.997 / 1.998$ \\
\hline & La Molina, Lima & 240 & $12^{\circ} 05^{\prime} \mathrm{S}$ & $\begin{array}{c}1.994 / 1.995 / 1.996 / 1.997 / 1.998 / 2.001 / \\
2.002\end{array}$ \\
\hline & Barranca, Lima & 280 & $10^{\circ} 45^{\prime} \mathrm{S}$ & 2.001 \\
\hline & Huacho, Lima & 180 & $11^{\circ} 06^{\prime} \mathrm{S}$ & 2.000 \\
\hline & Canta, Lima & 700 & $11^{\circ} 28^{\prime} \mathrm{S}$ & 1.995 \\
\hline & Mala, Lima & 350 & $12^{\circ} 39^{\prime} \mathrm{S}$ & 1.995 \\
\hline & Cañete, Lima & 250 & $13^{\circ} 04^{\prime} \mathrm{S}$ & $1.995 / 2.000 / 2.001$ \\
\hline & Nasca, Ica & 650 & $14^{\circ} 49^{\prime} \mathrm{S}$ & 1.993/1.994/1.995/1.996/1.998 \\
\hline & Santiago, Ica & 330 & $14^{\circ} 11^{\prime} \mathrm{S}$ & $1.993 / 1.994$ \\
\hline & Tambo, Arequipa & 200 & $17^{\circ} 01^{\prime} \mathrm{S}$ & 1.996 \\
\hline & Moquegua, Moquegua & 300 & $17^{\circ} 11^{\prime} \mathrm{S}$ & 1.996 \\
\hline $20 \mathrm{I}$ & La Yarada, Tacna & 280 & $18^{\circ} 00^{\prime} \mathrm{S}$ & 1.995/1.996 \\
\hline
\end{tabular}

Tabla 2. Resultados de ensayos en diferentes localidades de trópico bajo, entre la Primavera-1.995 y Otoño-1.996.

\begin{tabular}{lccccccc}
\hline \multirow{2}{*}{ Variedad } & \multicolumn{3}{c}{ Primavera-1.995 } & \multicolumn{2}{c}{ Verano-1.996 } & Otoño-1.996 \\
& La Molina & Cañete & Nasca & Chanchamayo & Calana & Majes & Chanchamayo \\
\hline \multirow{2}{*}{ Reiche } & 46,5a & $11,1 \mathrm{~cd}$ & $17,0 \mathrm{~b}$ & $17,2 \mathrm{~b}$ & $32,1 \mathrm{c}$ & $24,0 \mathrm{ab}$ & $33,9 \mathrm{a}$ \\
UNICA & $27,8 \mathrm{~b}$ & $14,0 \mathrm{c}$ & $13,0 \mathrm{c}$ & $19,4 \mathrm{~b}$ & $58,8 \mathrm{a}$ & $23,7 \mathrm{ab}$ & $21,8 \mathrm{~b}$ \\
María Tambeña & $22,7 \mathrm{~b}$ & $9,7 \mathrm{~d}$ & $15,5 \mathrm{~b}$ & $6,9 \mathrm{~cd}$ & $18,3 \mathrm{~d}$ & $16,2 \mathrm{c}$ & $31,5 \mathrm{a}$ \\
Costanera & $13,1 \mathrm{c}$ & $18,0 \mathrm{~b}$ & $10,8 \mathrm{c}$ & $10,1 \mathrm{bc}$ & $35,1 \mathrm{c}$ & $14,2 \mathrm{c}$ & $16,2 \mathrm{bc}$ \\
Canchán & $5,3 \mathrm{~d}$ & $10,5 \mathrm{~d}$ & $5,8 \mathrm{~d}$ & $8,6 \mathrm{c}$ & $15,8 \mathrm{~d}$ & $24,4 \mathrm{~b}$ & $21,2 \mathrm{~b}$ \\
Tomasa T. Condemayta & $11,1 \mathrm{c}$ & $5,8 \mathrm{e}$ & $1,9 \mathrm{e}$ & $2,7 \mathrm{~d}$ & $12,1 \mathrm{e}$ & $13,9 \mathrm{~cd}$ & $14,6 \mathrm{c}$ \\
\hline Análisis de varianza & & & & & & & \\
\hline Cultivares & $* *$ & $* *$ & $* *$ & $*$ & $* *$ & $*$ & $*$ \\
Coef. Variabilidad (\%) & 18 & 26 & 23 & 36 & 27 & 25 & 33 \\
\hline
\end{tabular}

Diferentes letras denotan diferencias estadísticas significativas, según prueba de Waller-Duncan. Los signos $(*$ y **) representan niveles de significación a diferentes probabilidades (p), significativo: ${ }^{*} \mathrm{p}<0,05$, altamente significativo: ** $\mathrm{p}<0,01$. Fuente: CIP 1.997. 
Tabla 3. Resultados de ensayos en diferentes localidades de trópico bajo, en invierno-1.996.

\begin{tabular}{|c|c|c|c|c|c|c|}
\hline \multirow{2}{*}{ Variedad } & \multirow{2}{*}{$\begin{array}{c}\text { Tacna } \\
\text { Calana }\end{array}$} & \multirow{2}{*}{$\begin{array}{c}\text { Ica } \\
\text { Nasca }\end{array}$} & \multicolumn{2}{|c|}{ Arequipa } & \multirow{2}{*}{$\begin{array}{c}\text { Ancash } \\
\text { Chimbote }\end{array}$} & \multirow{2}{*}{$\begin{array}{l}\text { Moquegua } \\
\text { Moquegua }\end{array}$} \\
\hline & & & Majes & El Tambo & & \\
\hline María Tambeña & $79,7 \mathrm{a}$ & $63,1 b$ & $64,3 \mathrm{ab}$ & $41,1 \mathrm{a}$ & $5,7 \mathrm{c}$ & $21,2 \mathrm{a}$ \\
\hline Tomasa T. Condemayta & $65,8 a$ & $66,6 \mathrm{ab}$ & $74,3 a$ & $37,9 \mathrm{ab}$ & $19,9 a$ & $13,2 b$ \\
\hline Canchán & 51,9 bc & $71,1 \mathrm{a}$ & $52,0 \mathrm{c}$ & $37,6 \mathrm{ab}$ & $10,8 \mathrm{bc}$ & $4,1 \mathrm{~d}$ \\
\hline UNICA & $33,6 \mathrm{e}$ & $45,0 \mathrm{c}$ & $40,0 \mathrm{~d}$ & $30,0 \mathrm{c}$ & $13,2 \mathrm{~b}$ & $12,9 b$ \\
\hline Reiche & $42,4 d$ & $32,1 \mathrm{~d}$ & 30,0 e & $21,2 d$ & $14,9 \mathrm{~b}$ & $9,2 \mathrm{c}$ \\
\hline Costanera & $43,2 d$ & $27,8 \mathrm{e}$ & $20,3 f$ & $8,4 \mathrm{e}$ & $8,4 \mathrm{c}$ & $4,4 \mathrm{~d}$ \\
\hline \multicolumn{7}{|l|}{ Análisis de varianza } \\
\hline Cultivares & $*$ & $* *$ & $* *$ & $*$ & $* *$ & $* *$ \\
\hline Coef. Variabilidad (\%) & 31 & 21 & 15 & 27 & 18 & 22 \\
\hline
\end{tabular}

Diferentes letras denotan diferencias estadísticas significativas, según prueba de Waller-Duncan. Los signos $(*$ y **) representan niveles de significación a diferentes probabilidades (P), significativo : ${ }^{*} \mathrm{P}<0,05$, altamente significativo: ** $\mathrm{P}<0,01$. Fuente: CIP 1.997.

Ensayos para evaluar el efecto de las interacciones ambientales (Vásquez, 2002), fueron realizados en tres épocas (otoño-1.997, invierno-1.997, primavera-1.997) y en tres localidades (Nasca, La Molina y Trujillo). Desde el intermedio de las evaluaciones coincidieron con el fenómeno del El Niño, presentado entre 1.997-98. A partir de 29 factores climáticos y edáficos medidos en nueve momentos, en cosechas a los 90 días después de la siembra, se realizó el análisis de componentes principales, el mismo que con dos de los primeros componentes expresaron el $78 \%$ de la variabilidad total de los datos.

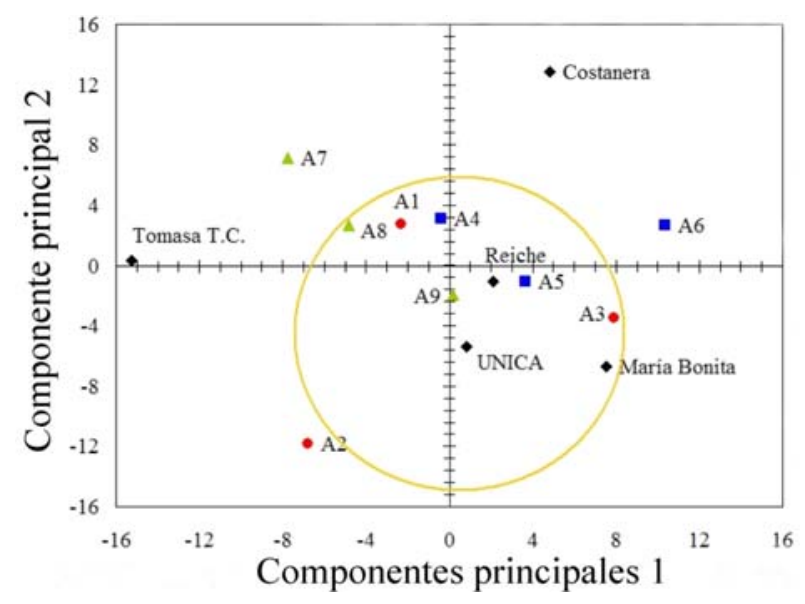

La variedad UNICA y Reiche fueron los que más se adaptaron a las combinaciones de los tres ambientes y las tres épocas del cultivo, tal como lo muestra el gráfico en la Figura 4 (ver círculo naranja que denota el grado de asociación de la variedad UNICA con al menos seis de las nueve combinaciones). Sin embargo, la baja correlación entre la temperatura máxima y el contenido de glicoalcaloides totales del tubérculo, entre los diferentes ambientes para la variedad UNICA $(r=0,2)$, es una ventaja con respecto la variedad Reiche que presenta una alta correlación ( $r=0,8)$ (Vásquez, 2002).
Figura 4. Componentes principales 1 y 2, con el 78\% de la variabilidad total.

En localidades, A1, A2 y A3: Trujillo. A4, A5 y A6: La Molina, Lima. A7, A8 y A9: Nasca, Ica. En épocas, A1, A4 y A7: otoño-1.997. A2, A5 y A8: invierno-1.997. A3, A6 y A9: primavera-1.997. Fuente: Vásquez, 2002. 


\section{Resistencia a factores bióticos}

El CIP ha establecido una estandarización de las evaluaciones en experimentos homogéneos que busquen determinar niveles de resistencias, tolerancias o susceptibilidad a los diferentes factores bióticos (virus, tizón tardío, nematodo, marchitez bacteriana, mosca minadora), con ese fin se realizan evaluaciones en el Standard Evaluation Trials -SET, según los diferentes protocolos (CIP, 2006 y 2007), a continuación se presentan algunos resultados relacionados con la variedad UNICA (Tabla 4).

Tabla 4. Reacción a Enfermedades para las Variedades UNICA, Canchán y Tomasa.

\begin{tabular}{lccc}
\hline \multirow{2}{*}{ Enfermedad } & \multicolumn{3}{c}{ Variedades } \\
\cline { 2 - 4 } & UNICA & Canchán & Tomasa \\
\hline PVY & ER & S & S \\
PVX & S & R & S \\
PLVR & MR & S & R \\
$\begin{array}{l}\text { Rancha } \\
\text { (Phytophthora infestans) }\end{array}$ & LR & LR & S \\
$\begin{array}{l}\text { Mosca Minadora } \\
\text { (Liriomyza huidobrensis) } \\
\begin{array}{l}\text { Marchitez Bacteriana } \\
\text { (Ralstonia solanacearum) }\end{array}\end{array}$ & $\mathrm{S}$ & $\mathrm{S}$ & $\mathrm{S}$ \\
$\begin{array}{l}\text { Nematodo del Nudo } \\
\text { (Meloidogyne ssp.) }\end{array}$ & $\mathrm{MR}$ & $\mathrm{S}$ & $\mathrm{MR}$ \\
\hline
\end{tabular}

Donde: S=Susceptible, LR=Ligeramente Resistente, $\quad$ MR=Moderadamente Resistente, R=Resistente, ER=Extremadamente Resistente. (CIP, 2006).

Para el caso del PVY se realizó la prueba de inoculación mecánica y prueba de injerto en invernadero, en ambas resulta negativa a la prueba de Enzyme-Linked Immunosorbent Assay - ELISA, lo cual se considera como resistente. Para la evaluación del PVX se realizó igualmente la prueba de inoculación mecánica y prueba de injerto en invernadero, en ambas resulta positiva a la prueba de ELISA, lo cual se considera como susceptible. En la evaluación del PLRV se realizó por infección natural en campo, sembrándose por tres campañas consecutivas, después de la tercera campaña y realizada la prueba de ELISA, el cultivar UNICA solo había sido infectado en $15,8 \%$ de las plantas sembradas, lo cual es considerado resistente (CIP, 2006 y 2007).

La evaluación de rancha o tizón tardío (Phytophthora infestans) considera siembra en dos ambientes, describiendo como ataque moderado a la zona de Comas, Junín, Perú y como ataque severo a la zona de Oxapampa, Cerro de Pasco, Perú (CIP, 2.006). En cada caso se midió el nivel de daño por la rancha en las hojas, obteniéndose el Área Bajo la Curva del Progreso de la Enfermedad (Area Under the Disease Progress Curve - AUDPC), que para el caso del cultivar UNICA se obtuvo 964 de AUDPC en ataque moderado (Control resistente: 750 / Control susceptible: 1.230) y 2.901 de 
AUDPC en ataque severo (Control resistente: 1387 / Control susceptible: 2835). En tal sentido se considera como ligeramente tolerante a rancha o tizón tardío (Phytophthora infestans).

La evaluación para mosca minadora (Liriomyza huidobrensis) considera dos momentos, cuando la población de la plaga es baja denominada presión intermedia y cuando la población es mayor denominada presión alta, en ambos casos la localidad para evaluación es Cañete-Lima. Se mide el daño en las hojas por efecto de la larva de la mosca, el mismo que se cuantifica en tres momentos de desarrollo del cultivo. Cuando el nivel de daño esta por debajo de $40 \%$ al final de la presión intermedia, se realiza una segunda evaluación en presión intermedia y se somete a una primera evaluación a presión moderada. El cultivar UNICA obtuvo un valor de 55,6\% en la primera evaluación de presión intermedia, considerándose como muy susceptible a mosca minadora (Liriomyza huidobrensis), no obstante existieron clones que estuvieron en valores de $100 \%$ de daño, mientras que el control tolerante alcanzó 17,2\% de daño (CIP, 2006).

La evaluación para nematodo del nudo (Meloidogyne ssp.) o RKN (Root Knot Nematodo), se realiza en invernaderos inoculando las macetas donde se siembra los tubérculos, posteriormente se cuentan el número de nódulos que se forman en las raíces (CIP, 2006). El cultivar UNICA resultó moderadamente resistente al nematodo del nudo (Meloidogyne ssp.).

La evaluación para marchitez bacteriana (Ralstonia solanacearum) se realiza en CarhuazAncash (CIP, 2006), haciéndose en un campo infectado con la bacteria, se realizan tres evaluaciones en diferentes momentos del cultivo, identificando la sintomatología. Como resultado se tiene que el cultivar UNICA presenta resistencia a marchitez bacteriana (Ralstonia solanacearum).

\section{Atributos para el mercado}

El principal uso que se le encuentra a la variedad UNICA es para el consumo en fresco, sin embargo también presenta atributos para el procesado de papas peladas y cortadas en tiras (CIP, 2002), utilizada comúnmente en el Perú como guarnición para los pollos a la brasa, teniendo un 58\% de rendimiento en procesamiento para tiras mayores de $8 \mathrm{~cm}$ (Tabla 5 y Figura 4) sobre el rendimiento total.

Tabla 5. Promedio de rendimiento total y de procesamiento en tiras, en localidades de Huancayo, Junín y Chaglla, Huánuco; Perú.

\begin{tabular}{|c|c|c|c|c|c|}
\hline \multirow[b]{2}{*}{ Variedad } & \multirow{2}{*}{$\begin{array}{c}\text { Rdto. } \\
\left(\mathrm{t} \cdot \mathrm{ha}^{-1}\right)\end{array}$} & \multicolumn{3}{|c|}{ Porcentaje sobre rendimiento total (\%) } & \multirow{2}{*}{$\begin{array}{c}\text { Rendimiento en } \\
\text { tiras }>8 \mathbf{~ c m} \\
\left(\mathbf{t} \cdot \mathbf{h a}^{-1}\right)\end{array}$} \\
\hline & & Comercial & Pelado-Retocado & Tiras $>8 \mathrm{~cm}$ & \\
\hline Canchán & 51 & 85 & 64 & 31 & 16 \\
\hline Capiro & 43 & 83 & 58 & 32 & 14 \\
\hline Perricholi & 62 & 70 & 52 & 27 & 17 \\
\hline Tomasa T.C. & 43 & 81 & 56 & 28 & 12 \\
\hline UNICA & 40 & 88 & 71 & 58 & 23 \\
\hline Yungay & 58 & 79 & 58 & 30 & 17 \\
\hline
\end{tabular}

Fuente: CIP, 2002 


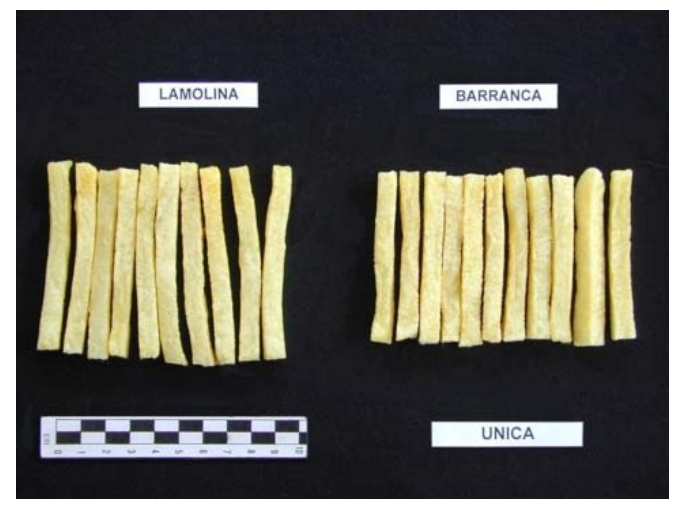

Figura 4. Procesamiento en tiras de la variedad UNICA para dos localidades.

El porcentaje de materia seca es de 19,06 $\pm 2,64$, en promedio de 8 localidades de la Costa Peruana (CIP, 1998). Los azucares reductores presentes en los tubérculos de la UNICA tiene un rango de 0,19 a 1,59\%, para tres localidades y tres épocas de siembra (Vásquez, 2003).

A partir de cuantificaciones realizadas de los glicoalcaloides totales (Vásquez, 2003), considerando solo dos localidades (Nasca, La Molina) y en tres épocas de siembra (otoño, invierno, primavera), se encontró un contenido promedio de 2,15 mg/100 g en peso seco (Figura 5), teniendo el menor coeficiente de variabilidad de 33\% con relación a las otras variedades evaluadas.

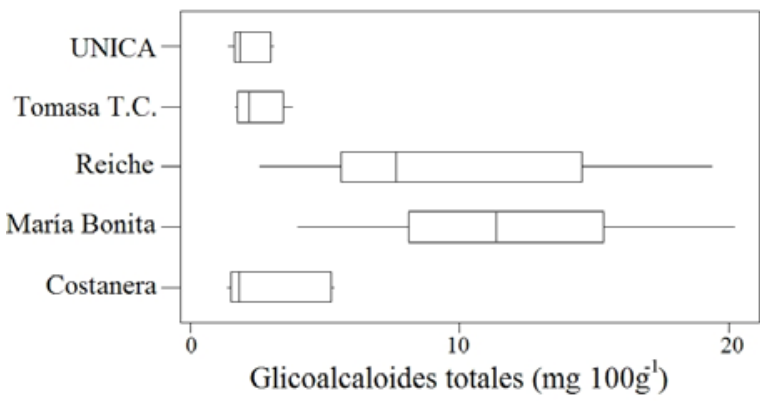

Figura 5. Distribución de la concentración de Glicoalcaloides totales en dos localidades y tres épocas de siembra. Fuente: Vásquez, 2.002.

Los valores de $\mathrm{Zn}$ y $\mathrm{Fe}$, considerados micronutrientes claves, así como la vitamina $\mathrm{C}$, fueron medidas por el proyecto financiado por Harvest Plus Challenge Program (CIP 2004), encontrándose contenidos de vitamina $\mathrm{C}, \mathrm{Fe}$ y Zn (miligramos por 100 gramos de peso seco), en valores cercanos y/o ligeramente superiores al de las variedades más difundidas (Tabla 6).

Tabla 6. Contenido de Vitamina C, Hierro y Zinc de Variedades Mejoradas. Localidad de Huancayo, Junín, Perú.

\begin{tabular}{|c|c|c|c|}
\hline Variedad & $\begin{array}{l}\text { Vitamina C } \\
\text { mg/100 g PS }\end{array}$ & $\begin{array}{c}\text { Fe } \\
\mathrm{mg} / 100 \mathrm{~g} P S\end{array}$ & $\begin{array}{c}\mathrm{Zn} \\
\mathrm{mg} / 100 \mathrm{~g} \text { PS }\end{array}$ \\
\hline Amarilis & $9,12 \pm 0,79$ & $0,32 \pm 0,04$ & $0,24 \pm 0,10$ \\
\hline Canchán & $10,46 \pm 1,02$ & $0,37 \pm 0,03$ & $0,27 \pm 0,13$ \\
\hline Reiche & $10,51 \pm 0,62$ & $0,46 \pm 0,02$ & $0,38 \pm 0,15$ \\
\hline UNICA & $10,57 \pm 0,47$ & $0,43 \pm 0,03$ & $0,35 \pm 0,14$ \\
\hline
\end{tabular}

Fuente: CIP, 2004. 


\section{Agradecimientos}

Al Ing Ricardo Espino Caballero de la Universidad Nacional "San Luis Gonzaga" de Ica, por su entusiasmo y abnegada labor en la selección y liberación de esta variedad. Al Proyecto PROMESPA-CIP, por su contribución en las etapas finales de validación y propagación de semillas. Al Proyecto FONTAGRO-CIP, por su contribución en la inscripción de la variedad al registro nacional de cultivares del SENASA, Perú.

\section{Literatura Citada}

CIP. 1997. Informe Técnico Anual 1.996-1.997 del Proyecto PROMESPA "Proyecto para el Mejoramiento y Semilla de Papa”. Centro Internacional de la Papa - CIP. Lima, Perú. 65 p.

CIP. 1998. Informe Técnico Anual 1.997-1.998 del Proyecto PROMESPA "Proyecto para el Mejoramiento y Semilla de Papa”. Centro Internacional de la Papa - CIP. Lima, Perú. 54 p.

CIP. 2002. Informe Técnico Anual 2.001-2.002 del Proyecto FONTAGRO "Selección y Utilización de Variedades de Papa con Resistencia a Enfermedades para el Procesamiento Industrial de América Latina”. Centro Internacional de la Papa - CIP. Lima, Perú. 84 p.

CIP. 2004. Progress Report: Improving micronutrient content of potato for reduced malnutrition. Centro Internacional de la Papa CIP to Harvest Plus Challenge Program. Lima, Perú. 11 p.
CIP. 2006. Standard Evaluation Trials - SET's. Base de datos de experimentos en el intranet del Centro Internacional de la Papa-CIP. Lima, Perú. http://sol/appdb/research/RIU/BREEDING/SET

1/ (Consultado en Agosto, 2.006)

CIP. 2007. Procedures for standard evaluation trials of advanced potato clones. An international cooperator's guide. Centro Internacional de la Papa - CIP. Lima, Perú. 126 p.

http://www.cipotato.org/publications/pdf/003875 .pdf (Consultado en Noviembre de 2.007)

Mendoza, G.; Espinoza, J.; Mendoza, H. y Bonierbale, M. 2003. "Reiche” (CIP 388611.22) Variedad de papa precoz, resistente a virus, tolerante al calor y de buena calidad industrial. Ponencia: II Congreso Científico de Invierno, organizado por Concytec. Universidad de Lima. 30 Jul - 2 Agosto 2.003. Lima, Perú. 6 p.

SENASA. 2005. Resolución Directoral No 3352.005-AG-SENASA-DGSV. Servicio Nacional de Sanidad Agraria - SENASA, Lima, Perú. 1 p.

UNICA. 1998. Nuevas variedades de papa con tolerancia al calor y calidad industrial: UNICA, Reiche. Tríptico informativo. Universidad Nacional "San Luis Gonzaga” de Ica - UNICA e Instituto Superior Tecnológico de Nasca. Ica, Perú. 6 p.

Vásquez, E. 2003. Influencia de los Factores Ambientales en la Predicción del Comportamiento de los Clones de Papa para la Costa del Perú. Universidad Nacional Agraria “La Molina”. Lima, Perú. 102 p. 